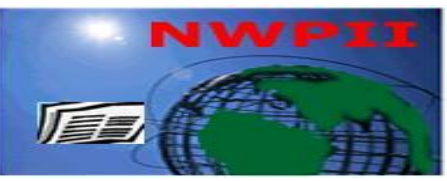

American Journal of Biomedical Sciences

ISSN: 1937-9080

nwpii.com/ajbms

\title{
Multiple Roles of Curcumin Attenuate High Fat Diet- Induced Kidney Cortex Derangement
}

\author{
Magda A Megahed ${ }^{1}$ \& Safia M Hassan ${ }^{2}$
}

\author{
${ }^{1}$ Biochemistry Department, Medical Research Institute, University of Alexandria, Egypt \\ ${ }^{2}$ Histochemistry and Cell Biology Department, Medical Research Institute, University of Alexandria, Egypt \\ *Corresponding Author \\ Safia M Hassan \\ Medical Research Institute, Alexandria University \\ 165, Horreya Avenue, Hadara, Alexandria \\ Egypt \\ Tel: +203 4282331, +2034282373 \\ Fax: +2034283719 \\ Email: dr_safiahassan@yahoo.com
}

Received: 04 October 2015; | Revised: 17 January 2016; | Accepted: 20 January 2016

\begin{abstract}
The urgency to develop renoprotective strategies sets the eyes in compounds as curcumin which prevents high fat diet-induced lipid accumulation and improves lipid profile in clinical studies. The present work aims to investigate the effect of curcumin on experimental nonalcoholic pattern kidney disease via histopathological, histochemical and immunohistochemical studies. Sixty Wister male rats weighing approximately 100 -120 grams were divided into 4 groups. Group I: 10 rats were served as control group and group II: 50 rats were received high fat diet for 12 weeks. Post histopathological confirmation of fatty kidney, this second group was subdivided into the following groups: Group III: 20 rats were injected intraperitoneally (I.P) with $1 \mathrm{ml} / \mathrm{kg}$ body weight dimethylsulfoxide (DMSO) day after day for 8 weeks. Group IV: 20 rats were injected I.P with $50 \mathrm{mg} / \mathrm{kg}$ body weight curcumin dissolved in DMSO, day after day for 8 weeks. The rest 10 rats in group II were sacrificed after 12 weeks from the beginning of experiment .Our histopathological results showed that renal structures of rats fed a high fat diet for 12 weeks had a dilatation in blood vessels and Bowman's space, mono nuclear cell infiltration, degeneration in nephrons and tubular defects. On the other hand rats treated with curcumin had nearly normal morphology of the kidney. Histochemical \& immunohistochemical results showed decreased catalase (CAT) activity $(96.08 \pm 2.74)$ and decreased nuclear factor-kappa B (122.82 \pm 5.44$)$, endothelial nitric oxide synthase (eNOS) (128.23 \pm 2.37$)$ and inducible nitric oxide synthase (iNOS) $(75.97 \pm 6.29)$ in fatty rats improved after using curcumin $(124.55 \pm 18.82),(135.69 \pm 6.39),(156.23 \pm 4.94)$ and $(95.39 \pm 4.21)$ respectively. In conclusion, curcumin attenuates high fat diet induced kidney cortex derangement.
\end{abstract}

Keywords: High fat diet, kidney cortex, curcumin, catalase, NF-kB, eNOS, and iNOS. 


\section{Background}

Kidney is an early responder to the challenge of high fat feeding. It exhibits an initial programmed inflammatory response [1].

De Castro et al (2013) [2] showed that high fructose diet (FRU) in adult's rats caused biggest change on metabolism of serum lipids and lipid accumulation in liver and kidney.

In the kidneys, the presence or absence of glomerular, sclerosis, necrosis, inflammation, fibrotic areas and deposition of lipid cells were evaluated [2].

Catalase is one of the key enzymes of the cellular antioxidant defense system which prevented free hydroxyl radical formation by decomposing hydrogen peroxide into oxygen and water [3].

NF-kB is a transcription factor present in the cytoplasm as an inactive heterotrimer consisting of five subunits including NF-kB1 $\left(\mathrm{P}^{50}\right.$ and $\left.\mathrm{P}^{105}\right)$, NF-kB2 $\left(\mathrm{P}^{52}\right)$, RelA $\left(\mathrm{P}^{65}\right)$, RelB and c-Rel. On activation, inhibitor kappa B kinas (IkBa) undergoes phosphorylation and ubiquitinationdependent degradation leading to release of NF$\mathrm{kB}$ from its cytoplasm location. This, in turn, give available transport into nucleus where it may bind to DNA and activate gene transcription [4]. It is widely present in varied cells, which could regulate a variety of cytokines involved in inflammation, adhesion molecules and protease gene transcription in vivo, and it is closely related with inflammation [5].

Adipose tissue has a role in secreting factor that impairs endothelial dependent dilatation via inhibition of $\mathrm{NO}$ synthase mediating NO production [6].

eNOS results in NO release from the endothelium of blood vessels and causes vasodilatation via cyclic guano sine monophosphate (CGMP). iNOS is an isozyme that is present in an oxidative environment $[7,8]$.

Curcumin is the active ingredient in the traditional herbal remedy and dietary spice turmeric (Curcuma longa). It is undergoing clinical trials for various diseases such as cancer, Alzheimer's disease, ulcerative colitis, etc [9].
The study of chronic progressive renal injury in rats is useful in the evaluation of strategies to reduce renal injury.

The present work, therefore, aims to investigate the effect of Curcumin on experimental nonalcoholic pattern kidney disease (histopathologicaly, histochemicaly and immunohistochemicaly).

\section{Materials and Methods}

This study was consisted of 60 Wister male rats weighing approximately 100-120 grams obtained from Animal House of Medical Research Institute of Alexandria University. Animals were housed with food and water ad libitum, stander light - dark cycle $(12: 12-\mathrm{h})$ at optimum temperature $\left(23 \pm 1 \mathrm{C}^{\circ}\right)$. Rats were divided into 4 groups.

Group I: 10 rats were served as control group that received standard rat chew diet.

Group II: 50 rats were received high fat diet (20\% protein, $20 \%$ fat, $5 \%$ fiber, $7 \%$ ash, and $6 \%$ vitamins in pellet form) for 12 weeks [10].

Post histopathological confirmation of fatty kidney, this group was subdivided into the following groups:

Group III: 20 rats were injected intraperitoneally (IP) with $1 \mathrm{ml} / \mathrm{kg}$ body weight dimethylsulfoxide (DMSO) (Sigma, Aldrich) day after day for 8 weeks.

Group IV: 20 rats were injected (IP) with 50 $\mathrm{mg} / \mathrm{kg}$ body weight Curcumin (sigma, Aldrich) dissolved in DMSO, day after day for 8 weeks [11].

The rest 10 rats in group II were sacrificed after 12 weeks from the beginning of experiment while rats in group III and group IV were sacrificed post 8 weeks from fatty kidney confirmation.

All animals' procedures were performed according to the principles in the Guide lines of Care and Use of Laboratory Animals, and were approved by the Institutional animal ethics committee.

The kidneys of all groups were subjected for the following:

1) Histopathological studies using $\mathrm{H} \& \mathrm{E}$ stains. 
2) Histochemical studies for catalase [12].

3) Immunohistochemical (IHC) studies for:

a. $\mathrm{NF}_{-\mathrm{k}} \mathrm{B}$ [13].

b. Endothelial nitric oxide synthase (eNOS) [14].

c. Inducible nitric oxide synthase (iNOS) [15].

\section{Statistical Analysis}

Quantitative assessments were performed and the number of positive cells in 5 randomly selected fields of view for each animal was averaged and expressed as total integrated optical density results are depicted as means \pm SD.

Statistical analysis was performed with Aperio - image scope software. The association between categorical variables, expression and clinical outcome, was estimated by post HOC test (LDS)

\section{Results}

The mean volumetric values of the glomeruli were mentioned in table 1 .

Table 1: Measurement of glomerular volumes in each group.

\begin{tabular}{|l|l|l|l|l||}
\hline Groups & Group I & Group II & Group III & Group IV \\
\hline Glom.vol. & $1211.06 \mu \mathrm{m}^{3}$ & $492.50 \mu \mathrm{m}^{3}$ & $528.86 \mu \mathrm{m}^{3}$ & $660.29 \mu \mathrm{m}^{3}$ \\
\hline
\end{tabular}

\subsection{Histopathological Results}

Group I: Kidney sections of control group stained with H\&E revealed normal histological structure of kidney cortex; well-developed glomeruli, distal and proximal convoluted tubules and macula densa (Fig. 1a).

Group II: Examination of renal structures of rats fed a high fat diet for 12 weeks showed a dilatation in blood vessels and Bowman's space, mono nuclear cell infiltration, degeneration in nephrons, including glomerular sclerosis and tubular defects (Fig. 1b).

Group III: At 8 weeks of DMSO treatment, rats showed minimal cortical regeneration with remaining the degenerated cells, minimal inflammation and congestion (Fig. 1c).

Group VI: The rats treated with curcumin had nearly normal morphology of the kidney (Fig. 1d).

\subsection{Histochemical results:}

\section{Catalase}

Group I: Histochemical localization of catalase was performed using DAB method and the results were dark brown granules with moderate catalase reaction which were distributed in the cytoplasm (Fig. 2a)

Group II: Examination of kidney sections showed weak catalase activity (Fig. 2b).

Catalase enzyme levels in kidney cortex decrease significantly $(\mathrm{P}<0.001)$ in HFD group compared to control group (Table 2).

Group III: After 8 weeks of DMSO, kidney sections exhibiting marked activity of catalase (Fig. 2c).

Group VI: Also marked activity of catalase was noticed in this group (Fig. 2d). Curcumin consumption significantly prevented this decrease levels $(\mathrm{P}<0.001)$ (Table 2). 

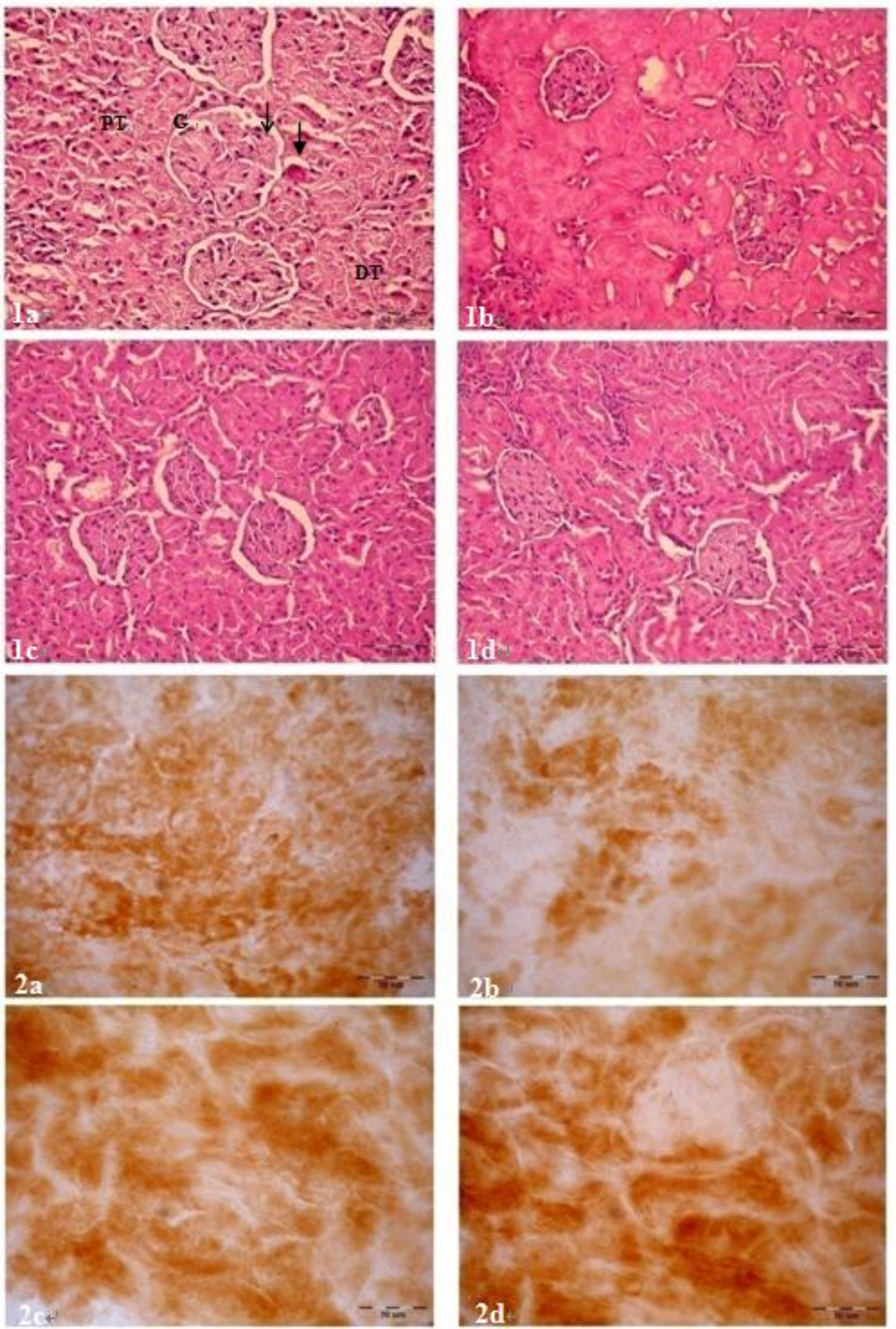

Figure 1: (a) Kidney section of control rat revealed normal histological structure: well-developed glomeruli (G), glomerular space $(\downarrow)$, distal convoluted tubules (DT), proximal convoluted tubules (PT) and macula densa ( $\downarrow$ ). (b) Rats fed on HFD for 12 weeks showed a dilatation in blood vessels and glomerular space. Mononuclear cell infiltration and tubular defects were also seen. (c) After 8 weeks of DMSO treatment: cortical regeneration with the presence of minimal inflammation and congestion. (d) After 8 weeks of curcumin treatment, rat sections showing nearly normal morphology of kidney cortex. (H $\& \mathrm{E}$ bar $=50 \mu \mathrm{m})$.

Figure 2: (a) Control rat kidney section showing moderate catalase activity as dark brown granules distributed in the cytoplasm. (b) Weak catalase activity. (c) Marked activity of catalase was shown. (d) Marked activity in most cortical cells was noticed in this group (DAB method, bar $=50 \mu \mathrm{m}$ ). 
Table 2: Comparison between the different studied groups according to catalase activity.

\begin{tabular}{|c|c|c|c|c|c|c|}
\hline & $\begin{array}{c}\text { Group I } \\
(\mathbf{n}=\mathbf{5})\end{array}$ & $\begin{array}{c}\text { Group II } \\
(\mathbf{n}=\mathbf{5})\end{array}$ & $\begin{array}{c}\text { Group III } \\
\quad(\mathbf{n}=\mathbf{5})\end{array}$ & $\begin{array}{c}\text { Group IV } \\
\quad(\mathbf{n}=\mathbf{5})\end{array}$ & $\mathbf{F}$ & p \\
\hline Min. - Max. & $128.4-150.55$ & $92.52-98.73$ & $98.84-120.03$ & $105.42-152.65$ & \multirow{3}{*}{$15.524^{*}$} & \multirow{3}{*}{$<0.001^{*}$} \\
\hline Mean \pm SD & $141.0 \pm 9.09$ & $96.08 \pm 2.74$ & $104.90 \pm 8.84$ & $124.55 \pm 18.82$ & & \\
\hline Median & 142.91 & 96.61 & 101.36 & 124.66 & & \\
\hline $\mathbf{p}_{1}$ & & $<0.001^{*}$ & $<0.001^{*}$ & $0.037^{*}$ & & \\
\hline $\mathbf{p}_{2}$ & & & 0.246 & $0.001^{*}$ & & \\
\hline
\end{tabular}

F: F test (ANOVA)

$\mathrm{p}_{1}$ : $\mathrm{p}$ value for Post Hoc Test (LSD) for comparing between Group I with each other groups

$\mathrm{p}_{2}$ : $\mathrm{p}$ value for Post Hoc Test (LSD) for comparing between Group II with each other groups

*: Statistically significant at $\mathrm{p} \leq 0.05$

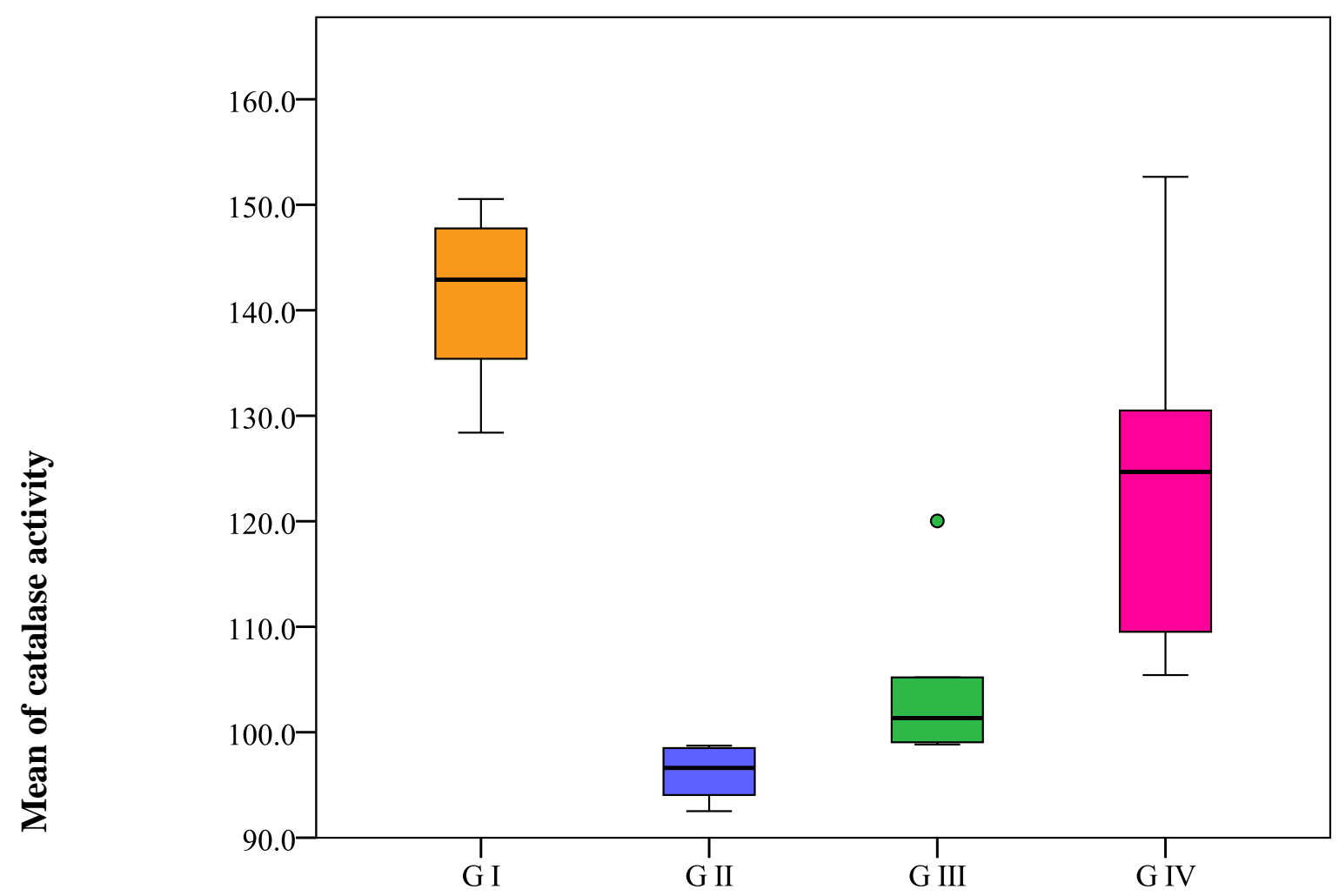

Figure 3: Comparison between the different studied groups according to catalase activity. 

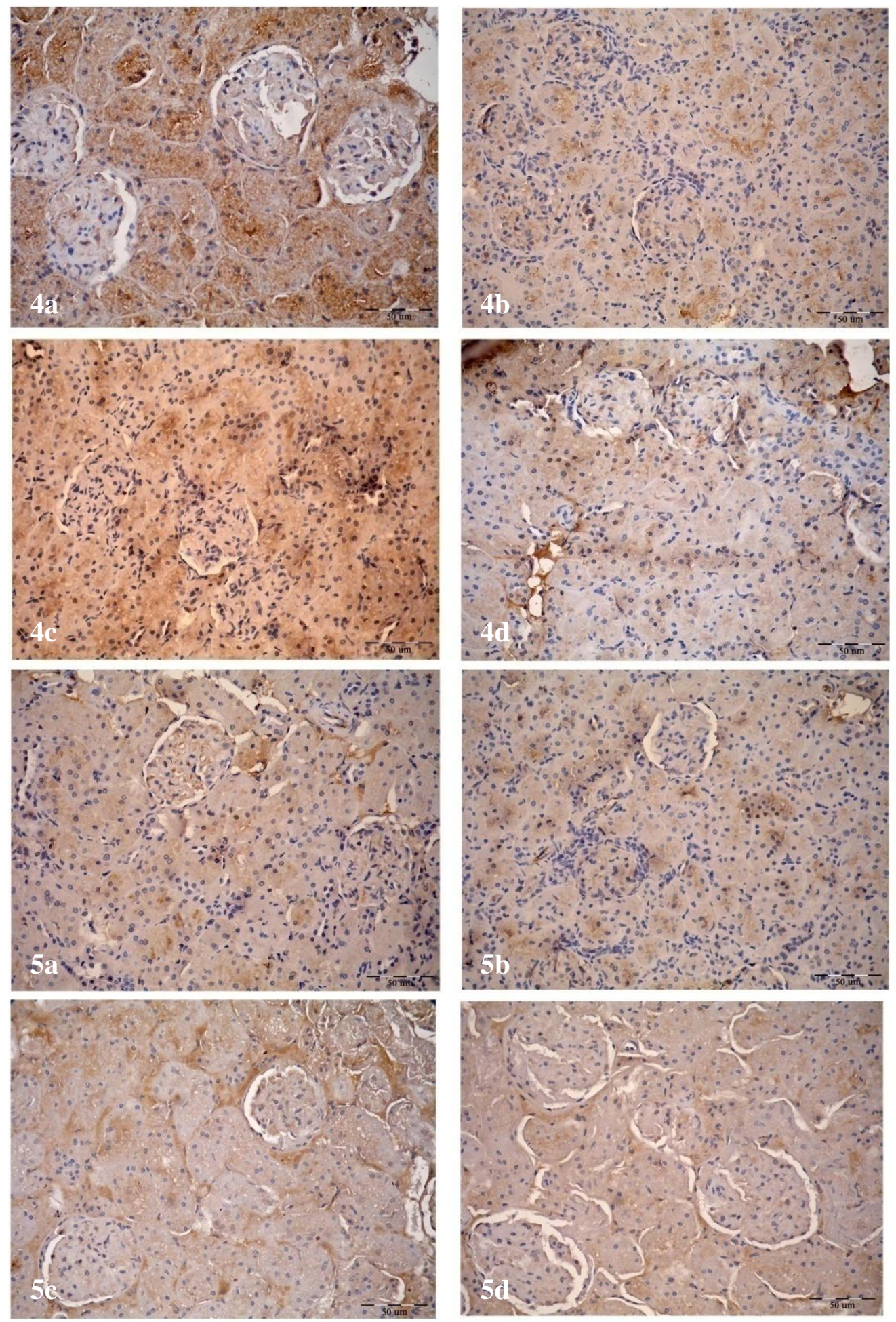

Figure 4: (a) Control section of rat kidney cortex showing moderate expression of $\mathrm{NF}-\mathrm{kB}$ as cytoplasmic brown staining cells. (b) We noticed weak expression of $\mathrm{NF}-\mathrm{kB}$ in comparison with control group. (c) $\mathrm{NF}-\mathrm{kB}$ expression was increased in the cytoplasm due to interaction with cytoplasmic NF - kB inhibitors. (d) Curcumin dose caused expression of $\mathrm{NF}-\mathrm{kB}$ in cortical nuclei. (IHC staining bar=50 $\mu \mathrm{m}$ ).

Figure 5: (a) Moderate expression of eNOS in rat kidney cortex was seen. (b) Weak expression of eNOS was seen in this group. (c) Increased expression of eNOS in this group.(d) Returned back normal expression of eNOS. (IHC staining bar $=50 \mu \mathrm{m})$. 

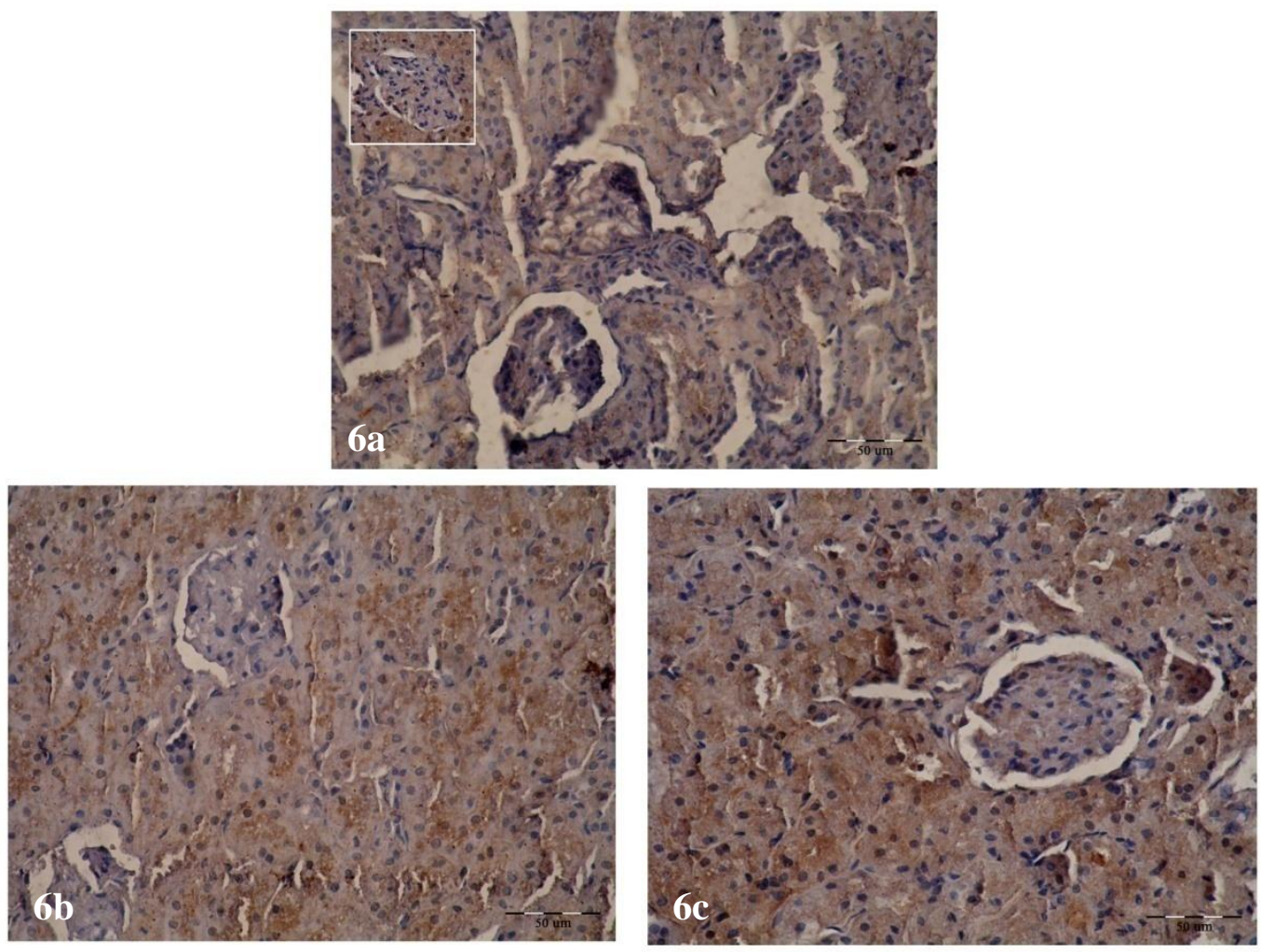

Figure 6: (inset) control section of rat kidney cortex showed moderate expression of iNOS. (a) HFD group showed weak expression of iNOS. (b) Expression of iNOS was increased.(c) Moderate expression of iNOS was seen but still not as control group (IHC stains bar $=50 \mu \mathrm{m}$ ).

\subsection{Immunohistochemical Result:}

\subsubsection{NF - kB}

Group I: NF - kB expression was detected as cytoplasmic brown staining cells of various intensities (Fig. 4a).

Group II: In this group decreased expressions of $\mathrm{NF}-\mathrm{kB}$ were noticed in comparison with control group (Fig.4b)

Group III: NF $-\mathrm{kB}$ dimmers are predominantly inactive (Fig. 4c).

Group IV: curcumin dose dependently blocked activated NF - kB (Fig. 4d).

$\mathrm{NF}-\mathrm{kB}$ expression in kidney cortex was decreased significantly $(\mathrm{P}<0.001)$ in $\mathrm{HFD}$ group compared to control group and each other groups (Table 3).

\subsection{2 eNOS \& iNOS}

Group1: Moderate expression of both eNOS and iNOS in kidney cortex (figs. 5a\&6 inset).

Group II: H.F.D group showing decreased expression of both eNOS and iNOS (figs. 5b\&6a).

Group III: In this group we noticed an increased expression of both eNOS and iNOS (figs. 5c\&6b).

Group IV: This group showed the recovery to near normal expression of both eNOS and iNOS but still not exact as control group (Figs. 5d\&6c).

We noticed that HFD significantly lowered $(\mathrm{P}<$ 0.001) renal NO levels in comparison with control while treatment with curcumin significantly elevated NO level of the rat consuming HFD (Tables 4\&5). 
Table 3: Comparison between the different studied groups according to NF-kB expression.

\begin{tabular}{|c|c|c|c|c|c|c|}
\hline & $\begin{array}{c}\text { Group I } \\
(n=5)\end{array}$ & $\begin{array}{c}\text { Group II } \\
(\mathbf{n}=\mathbf{5})\end{array}$ & $\begin{array}{l}\text { Group III } \\
\quad(n=5)\end{array}$ & $\begin{array}{c}\text { Group IV } \\
\quad(n=5)\end{array}$ & $\mathbf{F}$ & $\mathbf{p}$ \\
\hline Min. - Max. & $136.82-151.78$ & $118.02-130.78$ & $146.35-167.06$ & $129.18-145.36$ & & \\
\hline Mean \pm SD & $145.35 \pm 6.18$ & $122.82 \pm 5.44$ & $158.30 \pm 8.80$ & $135.69 \pm 6.39$ & $24.206^{*}$ & $<0.001^{*}$ \\
\hline Median & 146.98 & 120.97 & 157.71 & 134.41 & & \\
\hline $\mathbf{p}_{1}$ & & $<0.001^{*}$ & $0.008^{*}$ & $0.040^{*}$ & & \\
\hline $\mathbf{p}_{2}$ & & & $<0.001^{*}$ & $0.009^{*}$ & & \\
\hline
\end{tabular}

F: $F$ test (ANOVA)

p1: $p$ value for Post Hoc Test (LSD) for comparing between Group I with each other groups p2: $p$ value for Post Hoc Test (LSD) for comparing between Group II with each other groups

*: Statistically significant at $\mathrm{p} \leq 0.05$

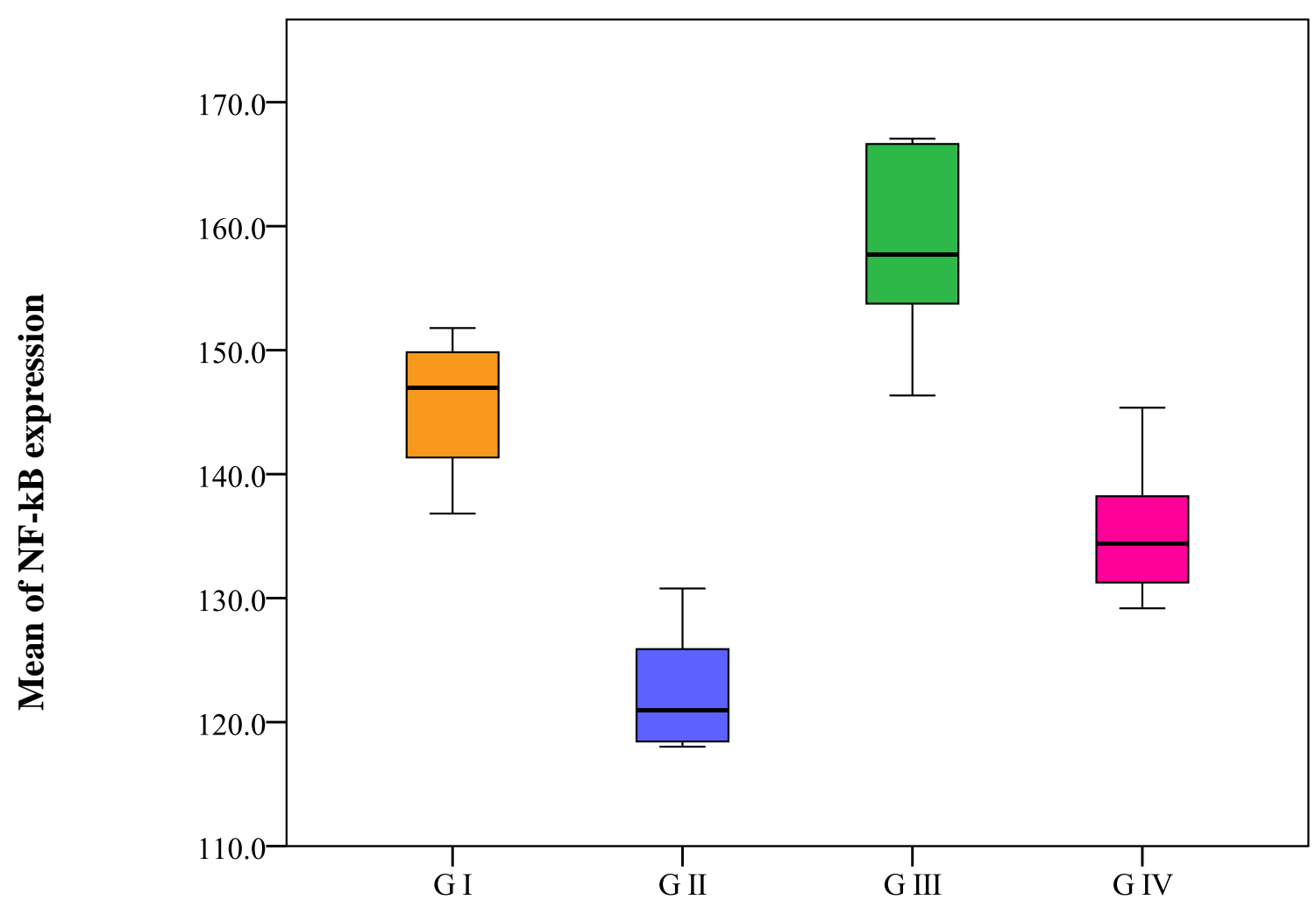

Figure 7: Comparison between the different studied groups according to NF-kB expression. 
Table 4: Comparison between the different studied groups according to eNOS expression.

\begin{tabular}{|c|c|c|c|c|c|c|}
\hline & $\begin{array}{c}\text { Group I } \\
(n=5)\end{array}$ & $\begin{array}{c}\text { Group II } \\
(n=5)\end{array}$ & $\begin{array}{l}\text { Group III } \\
\quad(n=5)\end{array}$ & $\begin{array}{c}\text { Group IV } \\
\quad(n=5)\end{array}$ & $\mathbf{F}$ & $\mathbf{p}$ \\
\hline Min. - Max. & $156.85-171.06$ & $125.65-132.10$ & $148.13-158.17$ & $150.34-162.48$ & \multirow{3}{*}{$64.259^{*}$} & \multirow{3}{*}{$<0.001^{*}$} \\
\hline Mean \pm SD & $164.55 \pm 5.40$ & $128.23 \pm 2.37$ & $153.27 \pm 4.11$ & $156.23 \pm 4.94$ & & \\
\hline Median & 165.54 & 127.71 & 153.46 & 157.43 & & \\
\hline $\mathbf{p}_{1}$ & & $<0.001^{*}$ & $0.001^{*}$ & $0.008^{*}$ & & \\
\hline $\mathbf{p}_{2}$ & & & $<0.001^{*}$ & $<0.001^{*}$ & & \\
\hline
\end{tabular}

F: F test (ANOVA)

p1: $p$ value for Post Hoc Test (LSD) for comparing between Group I with each other groups p2: $p$ value for Post Hoc Test (LSD) for comparing between Group II with each other groups

*: Statistically significant at $\mathrm{p} \leq 0.05$

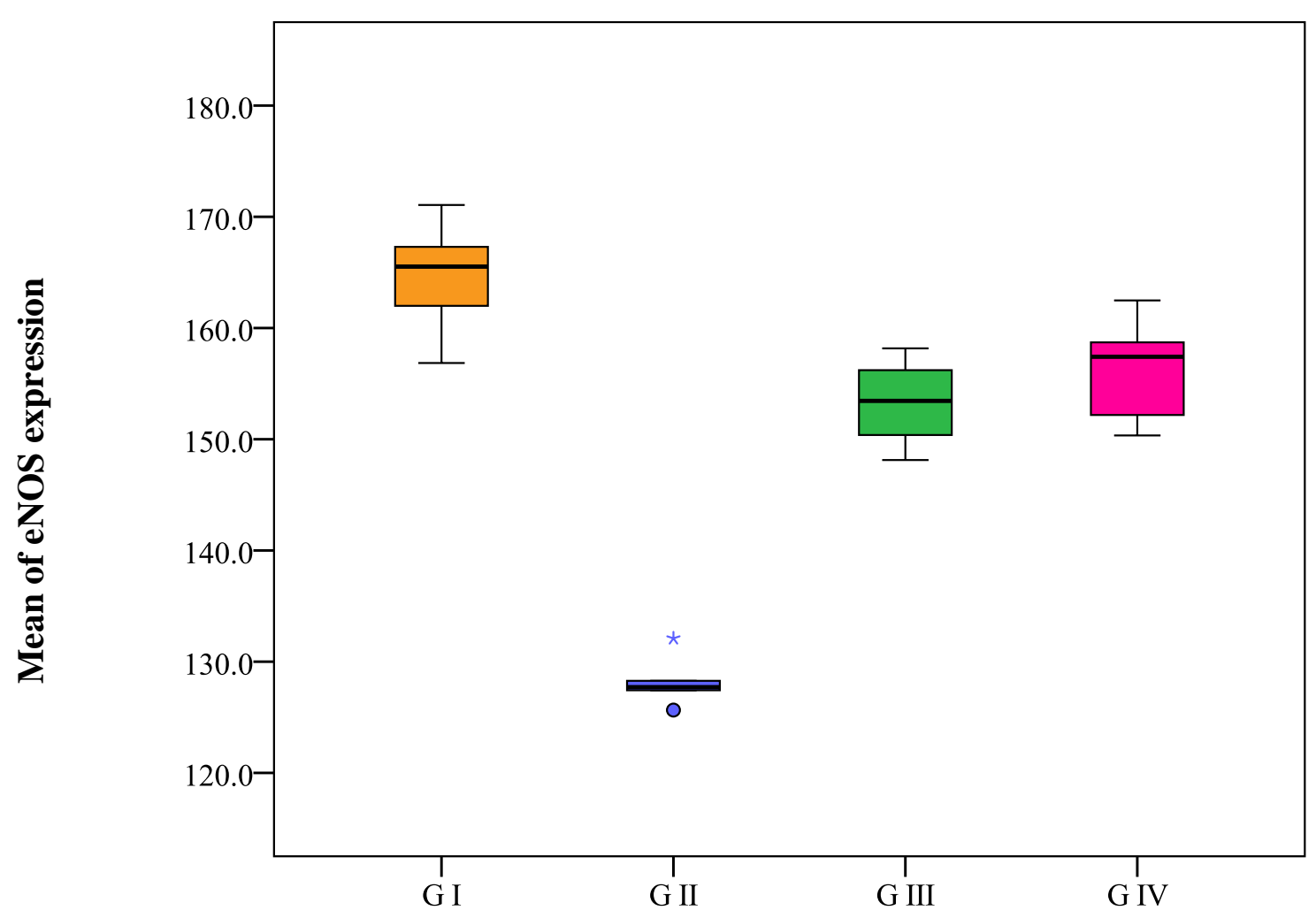

Figure 8: Comparison between the different studied groups according to eNOS expression. 
Table 5: Comparison between the different studied groups according to iNOS expression.

\begin{tabular}{|c|c|c|c|c|c|c|}
\hline & $\begin{array}{c}\text { Group I } \\
(n=5)\end{array}$ & $\begin{array}{c}\text { Group II } \\
(\mathbf{n}=\mathbf{5})\end{array}$ & $\begin{array}{l}\text { Group III } \\
\quad(\mathbf{n}=\mathbf{5})\end{array}$ & $\begin{array}{c}\text { Group IV } \\
\quad(n=5)\end{array}$ & $\mathbf{F}$ & $\mathbf{p}$ \\
\hline Min. - Max. & $94.64-113.83$ & $69.42-83.59$ & $74.86-95.68$ & $91.30-102.13$ & & \\
\hline Mean \pm SD & $104.60 \pm 7.25$ & $75.97 \pm 6.29$ & $85.51 \pm 8.54$ & $95.39 \pm 4.21$ & $16.729^{*}$ & $<0.001^{*}$ \\
\hline Median & 105.18 & 74.65 & 89.14 & 95.45 & & \\
\hline $\mathbf{p}_{1}$ & & $<0.001^{*}$ & $<0.001^{*}$ & $0.047^{*}$ & & \\
\hline $\mathbf{p}_{2}$ & & & $0.044^{*}$ & $<0.001^{*}$ & & \\
\hline
\end{tabular}

F: $F$ test (ANOVA)

p1: $p$ value for Post Hoc Test (LSD) for comparing between Group I with each other groups p2: $p$ value for Post Hoc Test (LSD) for comparing between Group II with each other groups

*: Statistically significant at $\mathrm{p} \leq 0.05$

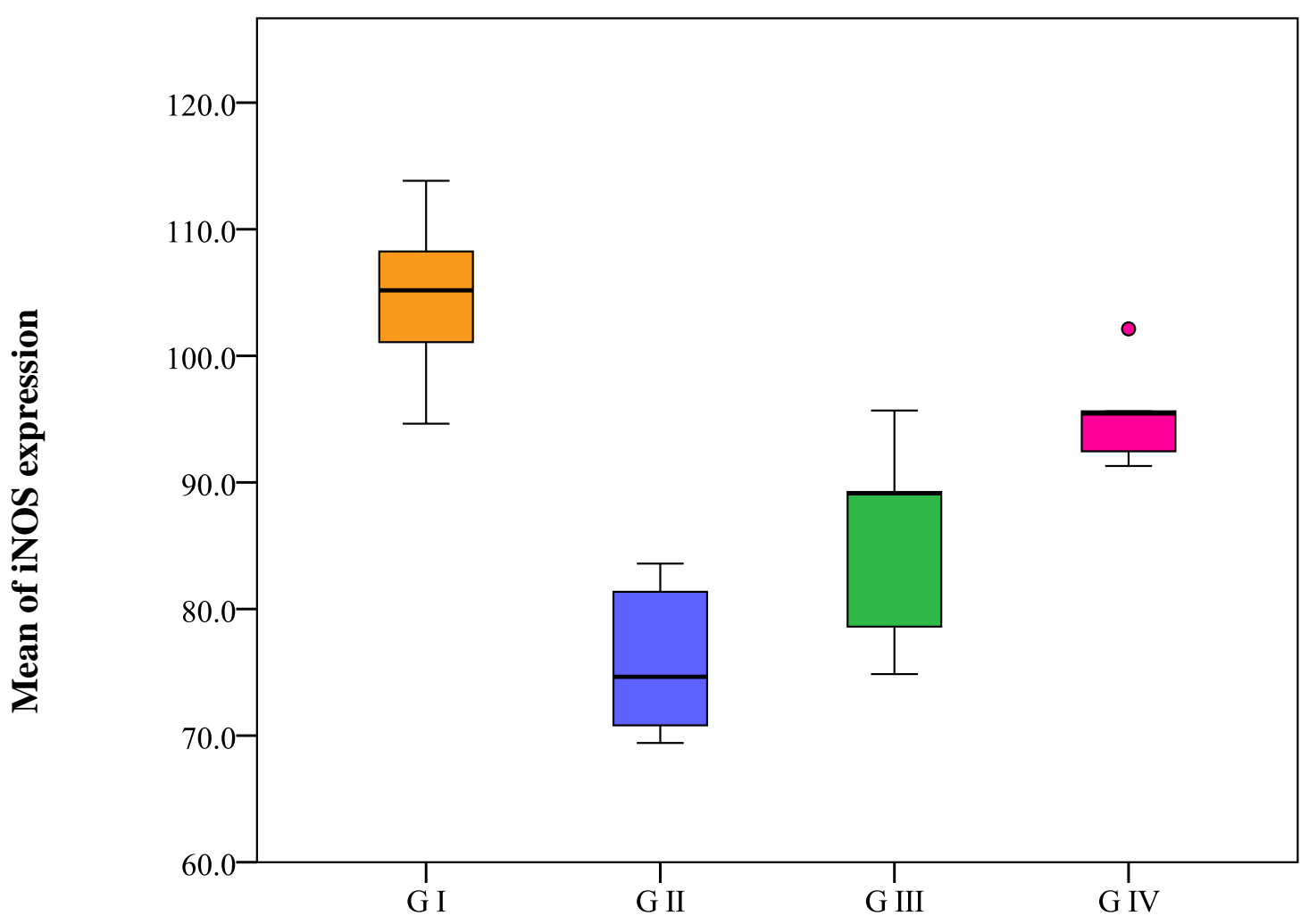

Figure (9): Comparison between the different studied groups according to iNOS expression. 


\section{Discussion}

The urgency to develop renoprotective strategies sets the eyes in compounds as cur cumin, which has been used in the traditional medicine, especially because its protective effects against renal damage [16].

Hall (2003) [17] has shown that an increase in blood pressure (BP) and development of central obesity are followed by renal disorders, such as vasodilatation, glomerular hyper filtration and inflammation. Similarly, Palanisamy et al (2008) [18] showed also various renal impairments, such as hypertrophy, arteriolopathy, cortical vasoconstriction, and hypertension and glomerular hyper filtration due to increased blood glucose. Our findings showed that renal structures of rats fed a high fat diet for 12 weeks showed a dilatation in blood vessels and Bowman's space, mono nuclear cell infiltration, degeneration in nephrons, including glomerular sclerosis and tubular defects, while rats treated with curcumin had nearly normal morphology of the kidney. Adult high fructose diet (FRU) rats had renal alterations such as accumulation of fat cells, increase in kidney weight, glomerular sclerosis and inflammatory infiltrates, along with elevated blood-glucose levels, reinforce the idea that glycosylation of proteins, the increased release of proinflammatory cytokines, oxidative stress, and the accumulation of lipid peroxidation products may be the cause of kidney damage [19].

Our findings were coincided with the clinical and experimental studies that have demonstrated the characteristic features of obesity-induced kidney injury include glomerular hypertrophy, thickening of the glomerular basement membrane, meningeal matrix expansion, and increased renal inflammation [20]. These alterations likely contribute to albuminuria, a progressive decline in renal function and ultimately glomerulosclerosis and tubulointerstitial fibrosis [20]. Moreover, Attunkaynak et al (2008) [21] concluded that a fatty diet is responsible for rats' obesity and may lead to renal deformities as a result of histopathological changes such as dilatation, tubular defects, inflammation and connective tissue enlargement of the kidney. Glomerular necrosis and atrophy, and basal membrane thickening were also noticed.

It is clear that curcumin protects the kidneys against ischemia/reperfusion $\mathrm{I} / \mathrm{R}$ injury via its antioxidant effects. On histological examination, rats treated with curcumin showed nearly normal morphology of the kidney [22]. Sankar et al (2012) [23] showed that cur cumin preserved the normal histological architecture of the liver, kidney and brain. Our present results were coincided with these findings where curcumin treated group recorded the restoring of nearly normal kidney features.

Regarding catalase reactions, Zargari et al (2013) [24] illustrated that curcumin ameliorated the toxicity of acetaminophen where it caused significant increase in the activity of CAT, SOD and TAC. Curcumin in another [cypermethrin model] caused significant and repair in the deterioration outcomes either of blood biochemical markers and liquid per oxidation or of antioxidant activity [23].

In support to this literature, our findings revealed that the curcumin treated group revealed a significant high catalase activity as compared with group II. These results were coincided with those of Megahed et al (2015) [25] where they found that histochemical results of catalase in livers' rats which fed on HFD revealed weak catalase activity compared to control group. Curcumin treatment showed marked catalase activity compared with DMSO group at the same period.

With respect to $\mathrm{NF}-\mathrm{kB}$, our present results showed that curcumin prevented the degradation of inhibitor of NF-kB (IkB) and hence NF-kB activation which caused by using HFD according to its anti-inflammatory and antioxidant properties. This may be due to the block of inhibitor kappa B Kinas (IKK)- mediated phosphorylation and degradation of $\operatorname{IKB} \propto$, thus $\mathrm{NF}-\mathrm{kB}$ remain bound to the inhibitor IKB $\propto$ in the cytoplasm and is not able to enter the nucleus [26]. This is, in turn, may explain the detection of cytoplasmic NF-kB in our findings and its absence in the nucleus

Our findings are coincided with Megahed et al (2015) [25] who revealed that the number of NF-kB positive cells in the curcumin group was 
significantly lower than that of the NAFL and DMSO groups and with many recent studies in various cell models which demonstrated that cur cumin targets the NF- $\kappa \mathrm{B}$ signaling pathway [27].

With respect to NOS, it plays an important role in the regulation of renal blood flow to the renal medulla and in the tubular regulation of sodium excretion. Rats fed HFD, resulted in decrease in serum and renal NOS production indicating that obese rats are more liable to develop hypertension.

In case of eNOS, our present results recorded a decrease in the enzyme in group II but there was an increase in group III \& group IV as compared with normal counterparts.

The decrement in group II may be due to increased fatty tissue that impaired the endothelial dependent dilatation and thus decrease NOS mediating NO product. The increment of eNOS in group IV could be due to improve NO levels via decreasing oxidative stress.

High levels of iNOS produce larger amounts of NO, which allows NO to react with superoxide forming peroxynitrite and thus leads to cell toxicity or death [8].

Our findings supported a lot of literature which confirmed that these changes improved by Garcinia that decreased the oxidative stress biomarkers and increased NO level [28].

Rise of oxidative stress and reduction in NO generation in micro vessels endothelial cells [29], suggesting that NO deficiency may contribute to renal vascular congestion and the renal dysfunction progression.

Furthermore, HFD -induced defects in NO production may promote the salt-sensitivity of blood pressure, which appears to require more NO to maintain blood pressure during a salt challenge [30].

Ramaswami et al (2004) [31] found that cur cumin could effectively block homocysteine (HC)-induced impairment of endotheliumdependent vasorelaxation, inhibit the $\mathrm{HC}$-induced epithelial nitric oxide synthase (NOS) expression, and block the effect of $\mathrm{HC}$ on superoxide anion production.

Curcumin derivatives have also been proved in ameliorating renal macrophage infiltration, and expression of the profibrotic cytokine TGF-B,
iNOS in diabetic rats nephropathy $[32,33]$. Additional studies in microglia cells (brain macrophage analogs) demonstrated reduced NO generation and protection of neural cells from oxidative stress following curcumin treatment, thus the spice may be useful in reducing the neuroinflammation associated with degenerative conditions such as Alzheimer's disease [34]. In conclusion, curcumin attenuates high fat diet induced kidney cortex derangement.

\section{References}

1. Declèves, A.E.; Mathew, A.V.; Cunard, R.; Sharma, K. AMPK Mediates the Initiation of Kidney Disease Induced by a High-Fat Diet. J Am Soc Nephrol, 2011, 22, 1846-1855 . DOI: 10.1681/ASN.2011010026

2. de Castro, U.G.; dos Santos, R.A.; Silva, M.E.; de Lima, W.G.; Campagnole-Santos, M.J.; Alzamora, A.C. Age-dependent effect of high-fructose and high-fat diets on lipid metabolism and lipid accumulation in liver and kidney of rats. Lipids Health Dis, 2013, 12, 136. DOI: $10.1186 / 1476-511 X-12-136$

3. Kim, B.Y.; Kim, H.J.; Lee, K.S.; Seo, S.J.; Jin, B.R. Catalase from the white-spotted flower chafer, Protaetia brevitarsis: cDNA sequence, expression, and functional characterization. Comp Biochem Physiol B Biochem Mol Biol, 2008; 149 (1): 183-190. DOI: 10.1016/j.cbpb.2007.09.007

4. Ghosh, S.; Karin, M. Missing pieces of the NF-кB puzzle. Cell, 2002, 109, 81-96. DOI: $10.1016 / \mathrm{S} 0092-8674(02) 00703-1$

5. Kaidashev, I.P. NF-kB activation as a molecular basis of pathological process by metabolic syn $\neg$ drome. Fiziol Zh, 2012, 58, 93-101.

6. Payne, G.A.; Bratz, I.N.; Dick, G.M.; Tune, J.D. Endogenus adipose derived factor diminish coronary endothelial function via inhibition of nitric acid synthase. Micro Circulation, 2008, 15(5), 417- 426. 
DOI: $10.1080 / 10739680701858447$

7. Ak, T.; Gülçin, I. Antioxidant and radical scavenging properties of curcumin. ChemicoBiological Interactions, 2008, 174, 27-37. DOI: 10.1016/j.cbi.2008.05.003

8. Ali, B.H.; Al-Wabel, N.; Mahmoud, O.; Mousa, H.M.; Hashad, M. Curcumin has a palliative action on gentamicin-induced nephrotoxicity in rats. Fundamental \& Clinical Pharmacology, 2005, 19, 473-477. DOI: 10.1111/j.1472-8206.2005.00343.x

9. Gupta, S.C.; Patchva, S.; Aggarwal, B.B. Therapeutic Roles of Curcumin: Lessons Learned from Clinical Trials. AAPS J, 2013, 15, 195-218. DOI: 10.1208/s12248-0129432-8

10. Fiorese, M.; Fernanda, O.; Flavia, R.; Nadia, C.; Marla, S.; Keico, O. Efficiency of intermittent exercise on adiposity and fatty liver in rats fed with high-fat diet. Obesity, 2008, $\quad 16, \quad 2217-2222$. DOI: 10.1038/oby.2008.339

11. Vizzutti, F.; Provenzano, A.; Galastri, S.; Milani, S.; Delogu, W.; Novo, E. Curcumin limits the fibrogenic evolution of experimental steatohepatitis. Lab Invest, 2010, 90(1), 104-115. DOI: $10.1038 /$ labinvest.2009.112

12. Kiernan, J.A. Histological and Histochemical methods: Theory and Practice. 3rd ed. Oxoford University Press Inc, 2001; pp 328333, 373-375.

13. Lessard, L.; Bégin, L.R.; Gleave, M.E.; MesMasson, A.M.; Saad, F. Nuclear localization of the nuclear factor kappa-B transcription factors in prostate cancer: an immunohistochemical study. $\mathrm{Br} \mathrm{J}$ Cancer, 2005, 93, 1019-1023. DOI: $10.1038 /$ sj.bjc.6602796

14. Lamas, S.; Marsden, P.A.; Li, G.K.; Tempst, P.; Michel T. Endothelial nitric oxide synthase: molecular cloning and characterization of a distinct constitutive enzyme isoform. Proc Natl Acad Sci U S A, 1992, 89(14), DOI: $10.1073 /$ pnas.89.14.6348
15. Goto, S.; Yamamoto, T.; Feng, L.; Yaoita, E.; Hirose, S.; Fujinaka, H. Expression and localization of inducible nitric oxide synthase in anti-Thy-1 glomerulonephritis. Am J Pathol, 1995, 147 (4), 1133-1141.

16. Tapia, E.; Zatarain-Barrón, Z.L.; HernándezPando, R.; Zarco-Márquez, G.; Molina-Jijón, E.; Cristóbal-García, M. Curcumin reverses glomerular hemodynamic alterations and oxidant stress in 5/6 nephrectomized rats. Phytomedicine, 2013, 20, 359-366. DOI: $10.1016 /$ j.phymed.2012.11.014

17. Hall, J.E. The kidney, hypertension, and obesity. Hypertension, 2003, 41, 625-633. DOI: 10.1161/01.HYP.0000052314.95497.78

18. Palanisamy, N.; Viswanathan, P.; Anuradha, C.V. Effect of genistein, a soy isoflavone, on whole body insulin sensitivity and renal damage induced by a high-fructose diet. Ren Fail, 2008, 30: 645-54. DOI: $10.1080 / 08860220802134532$

19. Sasson, A.N.; Cherney, D.Z. Renal hyperfiltration related to diabetes mellitus and obesity in human disease. World $\mathbf{J}$ Diabetes, 2012, 3: 1-6. DOI: $10.4239 /$ wjd.v3.i1.1

20. Pereira-Lancha, L.O.; Campos-Ferraz, P.L.; Lancha, A.H. Obesity: considerations about etiology, metabolism, and the use of experimental models. Diabetes Metab Syndr Obes, 2012, 5: 75-87. DOI: $10.2147 / \mathrm{DMSO}$. S25026

21. Altunkaynak, M.E.; Ozbek, E.; Altunkaynak, B.Z.; Can, I.; Unal, D.; Unal, B. The effects of high-fat diet on the renal structure and morphometric parametric of kidneys in rats. $\mathbf{J}$ Anat, 2008, 212 (6), 845-852. DOI: $10.1111 /$ j.1469-7580.2008.00902.x

22. Bayrak, O.; Uz, E.; Bayrak, R.; Turgut, F.; Atmaca, A.F.; Sahin, S. Curcumin protects against ischemia/reperfusion injury in rat kidneys. World J Urol, 2008, 26(3), 285-291. DOI: $10.1007 / \mathrm{s} 00345-008-0253-4$

23. Sankar, P.; Telang, A.G.; Manimaran, A. Protective effect of curcumin on cypermethrin-induced oxidative stress in 
Wistar rats. Exp Toxicol Pathol, 2012, 64(5), 487-93. DOI: 10.1016/j.etp.2010.11.003

24. Zargari, M.; Ahmadi, S.; Shabani, S.; Mahrooz A. Protective Effect of Curcumin on the Superoxide Dismutase and Catalase Activity in Kidney of Acetaminophenexposed Rats. J Mazand Univ Med Sci, 2013, 23(97), 74-83.

25. Megahed, M.A.; Hassan, S.M.; Fayed, H.M.; Shamsyia, M.M.; Shaaban MM. The effect of curcumin on experimental non- alcoholic fatty liver disease in rat models: a biochemical, histochemical and immunohistochemical studies [Master Thesis]. Medical Research Institute, Egypt: University of Alexandria; 2015.

26. Buhrmann, C.; Mobasheri, A.; Busch, F.; Aldinger, C.; Stahlmann, R.; Montaseri A. Curcumin modulates nuclear factor kappaB (NF-kappaB)-mediated inflammation in human tenocytes in vitro: role of the phosphatidylinositol 3-kinase/Akt pathway. J Biol Chem, 2011, 286(32): 28556-28566. DOI: $10.1074 /$ jbc.M111.256180

27. Wang, D.; Veena, M.S.; Stevenson, K.; Tang, C.; Ho, B.; Suh JD. Liposome-encapsulated curcumin suppresses growth of head and neck squamous cell carcinoma in vitro and in xenografts through the inhibition of nuclear factor kappa B by an AKT-independent pathway. Clin Cancer Res, 2008, 14, 62286236. DOI: $10.1158 / 1078-0432 . C C R-07-$ 5177

28. Amin, K.A.; Kamel, H.H.; Abd Eltawab, M.A. Protective effect of Garcinia against renal oxidative stress and biomarkers induced by high fat and sucrose diet. Lipids Health Dis, 2011, 10, 6. DOI: 10.1186/1476-511X10-6

29. Savastano, D.M.; Covasa M. Adaptation to a high-fat diet leads to hyperphagia and diminished sensitivity to cholecystokinin in rats. J Nutr, 2005, 135(8):1953-9.

30. Morrison, R.G.; Mills, C.; Moran, A.L.; Walton, C.E.; Sadek, M.H.; Mangiarua, E.I. A moderately high fat diet promotes saltsensitive hypertension in obese zucker rats by impairing nitric oxide production. Clin Exp Hypertens, 2007, 29(6), 369-381. DOI: $10.1080 / 10641960701578360$

31. Ramaswami, G.; Chai, H.; Yao, Q.; Lin, P.H.; Lumsden, A.B.; Chen, C. Curcumin blocks homocysteine-induced endothelial dysfunction in porcine coronary arteries. J Vasc Surg, 2004, 40,1216-1222. DOI: 10.1016/j.jvs.2004.09.021

32. Pan, Y.; Wang, Y.; Cai, L.; Cai, Y.; Hu, J.; $\mathrm{Yu}, \mathrm{C}$. Inhibition of high glucose-induced inflammatory response and macrophage infiltration by a novel curcumin derivative prevents renal injury in diabetic rats. $\mathrm{Br} \mathrm{J}$ Pharmacol, 2012, 166(3), 1169-1182. DOI: $10.1111 /$ j.1476-5381.2012.01854.x

33. Pan, Y.; Zhu, G.; Wang, Y.; Cai, L.; Cai, Y.; $\mathrm{Hu}, \mathrm{J}$. Attenuation of high-glucose-induced inflammatory response by a novel curcumin derivative B06 contributes to its protection from diabetic pathogenic changes in rat kidney and heart. J Nutr Biochem, 2013, 24 (1), 146-1455. DOI: 10.1016/j.jnutbio.2012.03.012

34. He, L.F.; Chen, H.J.; Qian, L.H. Curcumin protects pre-oligodendrocytes from activated microglia in vitro and in vivo. Brain Res. 2010, 1339, 60-69. DOI: 10.1016/j.brainres.2010.04.014 